\title{
Spectral Characterization of Himalayan Near-Fault Ground Motion
}

60(2), pp. 205,215, 2016

DOI: 10.3311/PPci.7754

Creative Commons Attribution (1)

RESEARCH ARTICLE
Prabhat Kumar, Ashwani Kumar, Ashok Deota Pandey

Received 15-10-2014, accepted 10-08-2015

\begin{abstract}
Near-Fault Ground Motion (NFGM) spectral characteristics of three moderate-sized Himalayan earthquakes, viz., the 1986 Dharamsala earthquake $\left(M_{w}=5.5\right)$, the $1991 \mathrm{Ut}$ tarkashi earthquake $\left(M_{w}=6.8\right)$, and the 1999 Chamoli earthquake $\left(M_{w}=6.5\right)$ have been studied from the 33 available strong ground motion recordings. Pulse characteristics of fault-normal components in terms of pulse-periods and pulseindicators have been extracted adopting wavelet analysis. Seven mother wavelets were used in the analysis, and it was found that $d b 4$ and $d b 7$ mother wavelets were more efficient in extracting the pulse-type characteristics. NFGM spectra, at Bhatwari and Gopeshwar stations, showed higher spectral amplitudes in the velocity-sensitive and acceleration-sensitive regions compared to Indian codal response spectra. This is attributed to high PGV/PGA ratios. The study shows that NFGM leads to widening of acceleration-sensitive region, and the structures that are designed according to the Indian seismic code as flexible structures shall behave as stiff structures when subjected to NFGM.
\end{abstract}

\section{Keywords}

Himalayan Earthquakes - Indian Seismic Code · Near-Fault Ground Motion - Wavelet Analysis $\cdot$ Pulse-Characteristics $\cdot$ Response Spectra

\section{Prabhat Kumar}

Department of Earthquake Engineering, Indian Institute of Technology Roorkee, Haridwar, Uttarakhand, 247667, India

e-mail: prabhatkumariitr@gmail.com

\section{Ashwani Kumar}

Department of Earthquake Engineering, Indian Institute of Technology Roorkee, Haridwar, Uttarakhand, 247667, India

e-mail: ashwnfeq@iitr.ac.in

\section{Ashok Deota Pandey}

Department of Earthquake Engineering, Indian Institute of Technology Roorkee, Haridwar, Uttarakhand, 247667, India

e-mail: adpanfeq@gmail.com

\section{Introduction}

The three moderate-sized shallow-focus earthquakes namely, the 1986 Dharamsala earthquake $\left(M_{w}=5.5\right)$, the $1991 \mathrm{Ut}$ tarkashi earthquake $\left(M_{w}=6.8\right)$, and the 1999 Chamoli earthquake $\left(M_{w}=6.5\right)$ occurred in the Himalayan region. The Dharamsala earthquake occurred in the Kangra region of Himachal Lesser Himalaya, at the north-western edge of the rupture zone of great Kangra earthquake of 1905. This earthquake was recorded at nine stations of the Kangra strong motion array, deployed in the epicentral track of the Kangra earthquake in Himachal Pradesh [1]. The two moderate earthquakes, viz., the Uttarkashi earthquake and the Chamoli earthquake, occurred in the Garhwal Himalaya that form part of the Western Himalaya. These earthquakes caused severe damage in and around the Uttarkashi and Chamoli regions. The epicenters of these earthquakes were located in the seismic gap postulated between the rupture zones of the 1905 Kangra earthquake $\left(M_{w} \sim 8.0\right)$ and the 1934 Bihar-Nepal earthquake $\left(M_{w} \sim 8.4\right)$ [2]. The Uttarkashi earthquake was recorded at thirteen stations while the Chamoli earthquake was recorded at eleven stations of the strong motion array, deployed in the Garhwal and Kumaun Himalaya [3]. The purpose of this array was to measure the strong ground motion due to gap-filling earthquakes that were expected in the seismic gap. The strong motion recordings of these three moderate earthquakes have been analyzed for the purpose of identifying near-fault pulses. To allow for pulse detection, standard methodology proposed by [4] has been adopted. Near-fault pulses are attributed to forward directivity, fling, hanging wall and vertical effects [5]. Forward directivity occurs when the fault rupture propagates towards the site with a velocity close to the shear wave velocity. Further, sudden tectonic motions due to an earthquake can produce impulsive motions leading to permanent displacements at the site. Such motions have one sided velocity pulses [6.7]. Pulse-type ground motions possess immense damage potential, specifically for intermediate and longperiod structures [8]. Out of 33 strong ground motion recordings, only three recordings showed pulse-type characteristics. A brief description of the methodology employed for pulse detection, followed by comparison of spectral characteristics of near- 
fault pulse-type ground motions of the three Himalayan earthquakes with the Indian seismic (IS: 1893 (Part1): 2002) codal spectra forms the subject matter of this paper.

\section{Parameters of the Studied Earthquakes}

The parameters of the three moderate earthquakes in terms of their locations, origin times, magnitudes, and fault-plane solutions are listed in Table 1 and Table 2] The 1986 Dharamsala earthquake occurred in the Himachal Lesser Himalaya north of Dharamsala at an epicentral distance of $6 \mathrm{~km}$ and at a depth of about $7 \mathrm{~km}$. The region falls in seismic zone $\mathrm{V}$ of the seismic zoning map of India and can experience a probable maximum expected intensity of IX or more on the MM or MSK scales [9]. Dharamsala city lies in the vicinity of the Main Boundary Thrust (MBT), and the Main Central Thrust (MCT) falls further to the north at a distance of about $25 \mathrm{~km}$. The large number of earthquakes that occur between the MCT and the MBT define a belt, called the Main Himalayan Seismic Belt [10]. The Dharamsala earthquake has shown reverse faulting with right lateral strikeslip motion. The occurrence of this earthquake has been correlated with the southwest dipping splay between the MCT and the MBT [11]. The isoseismals of the 1986 Dharamsala earthquake are oval-shaped with the longest axis in the northwestsoutheast direction, and a maximum epicentral intensity of VIII on the MM scale was reported. The geometry of the isoseismals shows that attenuation of ground motion due to this earthquake has been more towards the northwest as compared to southeast [11].

The 1991 Uttarkashi earthquake occurred at a shallow depth of about $10 \mathrm{~km}$ north of the MCT in the Garhwal Himalaya. The epicenter of this earthquake fell at a distance of about $30 \mathrm{~km}$ northeast of the Uttarkashi station. The observed maximum epicentral intensity was IX on the MM scale in a region about $10 \mathrm{sq} \mathrm{km}$ around the epicentral zone. The observed intensity at Bhatwari and Uttarkashi stations were VIII+ on the MM scale [12]. The style of faulting associated with this earthquake as revealed from the fault-plane solutions given by various investigators indicated a low-angle thrust mechanism [10,13-15]. On the basis of isoseismals, iso-accelerations, aftershock locations and regional tectonics, the most probable source of this earthquake has been the Munsiari thrust, and the rupture seems to have propagated in the north to northwest direction [12,16]. The strong ground motion simulated using the envelope summation technique shows that the resultant envelope follows important strong motion characteristics such as directivity and attenuation effects, since the propagation of the rupture is towards Bhatwari along the modeled Munsiari thrust [16].

The 1999 Chamoli earthquake occurred about $100 \mathrm{~km}$ southeast of the 1991 Uttarkashi earthquake in the Garhwal Himalaya as a result of thrust faulting at a shallow depth of about $15 \mathrm{~km}$ [10]. The maximum intensity VIII on the MSK scale was observed in a region bound by the MCT to the north and the Alaknanda fault to the south [10]. The affected region lies in the seismic zone $\mathrm{V}$ of the seismic zoning map of India and the maximum anticipated intensity is IX or more in seismic zone V [9]. No expression of surface faulting was observed, however, the orientation of the elongated isoseismals indicated that the rupture seems to have propagated in a direction from east-northeast to west-southwest [17]. As the geometry of the largest intensity isoseismal is governed by the direction and style of rupture, the elongated isoseismal VII in the west-southwest to east-northeast direction indicates the strike of the fault and slip direction. It was observed that maximum damage was in the strike direction at some distance from the epicenter, and damage was lesser near the epicenter normal to strike direction. This was attributed to a slip that occurred on a low-angle thrust fault [17].

\section{Methodology Adopted for Pulse Detection}

The ground motion records (transverse (T) and longitudinal (L) components) obtained from the Dharamsala, Uttarkashi and Chamoli earthquakes have been analyzed with respect to source-site distance and peak ground acceleration (PGA) in order to select the strong ground motion records that may contain near-fault pulse in their ground motion. The 1986 Dharamsala earthquake was recorded by nine strong motion accelerographs placed at epicentral distances ranging from $5 \mathrm{~km}$ to $25 \mathrm{~km}$. 13 strong-motion accelerographs were triggered during the 1991 Uttarkashi earthquake. These accelerographs were located at distances ranging between 20 and $150 \mathrm{~km}$ from the epicenter. The 1999 Chamoli earthquake was recorded by eleven strong motion accelerographs located at distances ranging from $10 \mathrm{~km}$ to $120 \mathrm{~km}$ from the epicenter. Near-fault pulses are normally observed in the strong motion recordings obtained within 20 to $30 \mathrm{~km}$ from the epicenter [5, 18]. From the analysis of nearfault strong ground motion recordings of small and moderate earthquakes with peak ground accelerations (PGA) above $0.2 \mathrm{~g}$ (PGA $\geq 0.2 \mathrm{~g}$ ), [19] concluded that such recordings may contain near-fault pulses. Therefore, from the available 33 recordings, only three recordings within $30 \mathrm{~km}$ of epicenters $(\mathrm{D} \leq 30 \mathrm{~km})$ and with $P G A \geq 0.2 \mathrm{~g}$ were selected for pulse detection (Table 3). The epicenters of the three earthquakes along with the three station-locations are shown in the Fig. 1 .

Several models have been developed by various researchers to represent near-fault pulses [20,26]. These models are known as Equivalent Velocity Pulse (EVP) models. Mainly three parameters have been used to describe various types of pulse models, namely, the amplitude, the time-period, and the shape of the velocity pulse. Various pulse shapes have been used in the pulsemodels to represent the observed pulses in the velocity timehistory. Several mathematical techniques including some signal processing techniques have been adopted to represent the complex character of the velocity pulses. In recent years, the wavelet technique has been employed to extract pulse waveforms and the periods of velocity pulses from the velocity time-histories [4, 21, 27. In the present work, the methodology proposed by [4], which is based on wavelet theory, has been applied on the 
Tab. 1. Origin times, locations, focal depths and magnitudes of the studied earthquakes

\begin{tabular}{|c|c|c|c|c|c|c|c|c|c|}
\hline \multirow[t]{2}{*}{ Earthquake } & \multirow[t]{2}{*}{ Date } & \multicolumn{3}{|c|}{ Origin time (IST) } & \multicolumn{2}{|c|}{ Coordinates of epicenter } & \multirow{2}{*}{$\begin{array}{c}\text { Focal } \\
\text { depth }(\mathrm{km})\end{array}$} & \multirow[t]{2}{*}{$\mathbf{M}_{\mathbf{w}}$} & \multirow[t]{2}{*}{ Agency } \\
\hline & & $\mathrm{Hr}$. & Min & $\mathrm{Sec}$ & Lat. ${ }^{O} \mathrm{~N}$ & Long. ${ }^{O} \mathrm{E}$ & & & \\
\hline Dharamsala & $\begin{array}{c}\text { April } \\
26,1986\end{array}$ & 13 & 05 & 16.42 & 32.175 & 76.287 & 07 & 5.5 & USGS \\
\hline Uttarkashi & $\begin{array}{l}\text { October } \\
20,1991\end{array}$ & 02 & 53 & 16.45 & 30.780 & 78.770 & 10 & 6.8 & USGS \\
\hline Chamoli & $\begin{array}{c}\text { March } \\
29,1999\end{array}$ & 00 & 35 & 00.00 & 30.380 & 79.210 & 15 & 6.5 & $\begin{array}{c}\text { CMT } \\
\text { Harvard }\end{array}$ \\
\hline
\end{tabular}

Tab. 2. Fault-plane solutions of the studied earthquakes

\begin{tabular}{|c|c|c|c|c|c|}
\hline Earthquake & Plane & Strike $^{\mathrm{O}}$ & Dipo $^{0}$ & Slipo & Source \\
\hline \multirow[t]{2}{*}{ Dharamsala } & NP1 & 254 & 16 & 22 & $\begin{array}{c}\text { Molnar and } \\
\text { Lyon-Caen } 37 .\end{array}$ \\
\hline & NP2 & 143 & 84 & 105 & \\
\hline Uttarkashi & NP1* & 315 & 14 & 144 & Paul et al. 14. \\
\hline \multirow[t]{2}{*}{ Chamoli } & NP1 & 200 & 74 & 12 & $\begin{array}{c}\text { Kumar et al. } \\
38\end{array}$ \\
\hline & NP2 & 106 & 78 & 164 & \\
\hline
\end{tabular}

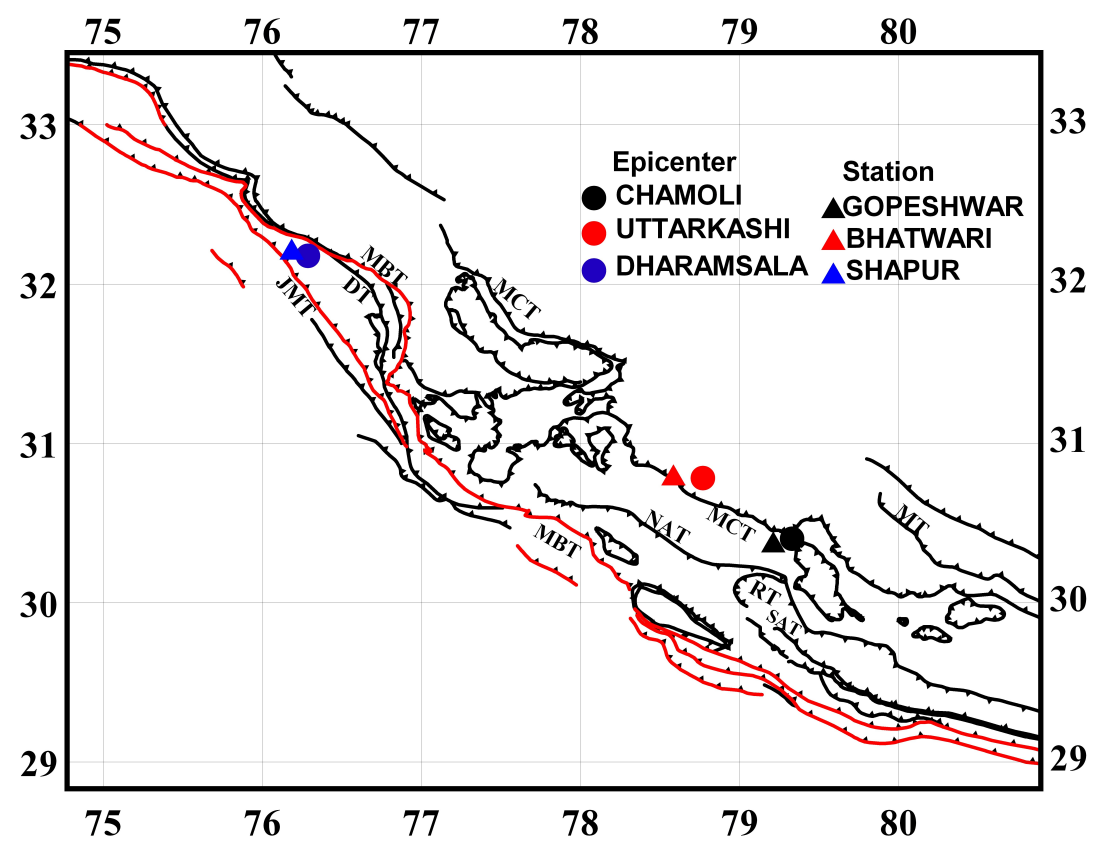

Fig. 1. Epicenters of the three earthquakes and the locations of stations that contain near-fault pulses

Tab. 3. Strong motion parameters of three selected recordings

\begin{tabular}{ccccccc}
\hline Earthquakes & Station & $\begin{array}{c}\text { Epi. Dist. } \\
(\mathbf{k m})\end{array}$ & $\begin{array}{c}\text { Component } \\
(\mathbf{L})\end{array}$ & PGA (g) & $\begin{array}{c}\text { Component } \\
(\mathbf{T})\end{array}$ & PGA (g) \\
\hline Dharamsala & Shapur & 11 & N75E & 0.21 & N15W & 0.25 \\
Uttarkashi & Bhatwari & 22 & N85E & 0.25 & N05W & 0.25 \\
Chamoli & Gopeshwar & 13 & N70W & 0.20 & N20E & 0.36 \\
\hline
\end{tabular}


three selected strong ground motion records that possibly contain near-fault pulses. Wavelet analysis is a new mathematical technique widely applied in signal processing. This technique is found to be much suitable to study non-stationary processes compare to the Fourier transform technique [28, 29].

The pulse-period forms a key parameter for structural engineers because the structural response due to pulse waveform or pulse-type motion depends on the ratio of fundamental period of the structure to the pulse-period [20, 21, 30, 35]. The wavelet analyses adopted by [4] have been implemented to extract the largest velocity pulse from a given ground motion for the purpose of finding the pulse-period (Tp) and location of the pulse in the velocity time-history. The pulse extracted using this procedure clearly captures the velocity pulse while filtering the high frequency ground motion contained in the original ground motion. This high frequency ground motion, after extracting the pulse from the original time-history, is called residual time-history. This technique can be used to extract a pulse from any type of ground motion whether a significant directivity pulse exists or not. The significance of pulse-type ground motion depends on the difference between residual and original time-history. Two predictor variables, i.e., peak ground velocity (PGV) ratio of the residual time-history to original time-history, and the energy ratio of the residual time-history to original timehistory, have been adopted as Pulse Indicator (PI) to predict the likelihood that a given record is pulse like or non-pulse like [4]. If the value of PI is above 0.85 , the record contains pulse-type ground motion; and if the value is below 0.15 , the record is nonpulse type. For computing PI the following expression Eq. (1) has been used [4].

$$
P I=\frac{1}{1+\exp (-23.3+14.6(\text { PGVratio })+20.5(\text { Energyratio }))} \ldots
$$

As the pulse-type ground motion due to directivity effect is more dominant in the $\mathrm{FN}$ direction [36], the recorded timehistories at Shapur, Bhatwari and Gopeshwar stations were oriented in FN direction for pulse extraction. For this purpose, the fault-plane solutions given in Table 2 have been adopted, and the method suggested by [36] has been used. The largest velocity pulses have been extracted, and their pulse-periods and pulse-indicators were predicted from these three fault-normal components using seven mother wavelets (Table 4). Daubechies (db4 and db7), Haar (haar), Symlet (sym4), Coiflets (coif2) are orthogonal wavelets, whereas, Reverse Biorthogonal (rbio2.4) and Biorspline (bior1.3) are bi-orthogonal wavelets [27]. The period associated with the maximum Fourier amplitude of a wavelet-pulse can be used to define a pseudo-period or pulseperiod (Tp) of the largest associated wavelet coefficient. This wavelet based pulse-period is free from user judgment and provides best pulse-period along with its occurrence in space and time [4]. Different mother wavelets, because of their variability, gave different values of pulse-indicators (PIs) and pulse-periods of the extracted long-period velocity pulses as tabulated in Ta- ble 4 It is evident from these values that at Shapur and Bhatwari stations, both Daubechies wavelets $\mathrm{db} 4$ and $\mathrm{db} 7$ are capable of extracting the pulse from the velocity time-history efficiently, as both have pulse-indicators (PIs) above 0.85. However, at Gopeshwar station, all the seven mother wavelets were capable of extracting the near-fault pulse from the ground motion since they had pulse-indicators (PIs) above 0.85 . The FN component and respective extracted pulses using different mother wavelets, having pulse-indicators greater than 0.85 (PI > 0.85) at Shapur, Bhatwari and Gopeshwar stations are shown in Fig. 2 to Fig. 4 No fling-step effect has been considered in pulse detection because the wavelet basis functions used for pulse extraction have zero residual displacement, so fling effect will not be detected [4].

\section{Interpretation of Results}

The pulse-periods (pseudo-period, Tp) of the estimated ground motion are different for extracted pulses which are associated with different type of mother wavelets. However, it is important to decide that which wavelet is better for extracting the parameters of the pulse-type ground motion amongst the seven mother wavelets. Researcher [20] estimated the pulseperiod (Tvp) of the velocity pulse by identifying a clear and global peak in the spectral-velocity response spectrum of the ground motion. This allowed for the estimation of pulse-period or equivalent pulse-period (Tvp) unequivocally. Researcher [34 found slightly higher value of pulse-period ( $\mathrm{Tp}$ ) compared to the value of pulse-period (Tvp) which they estimated from spectralvelocity response spectra using the method of zero crossing times, and the times at which velocity is equal to $10 \%$ of the peak velocity for the pulse. Further, it can be inferred from the wavelet analysis that the estimated pulse-period (Tp) is generally larger than the pulse-period (Tvp) estimated from spectral velocity response spectra [4]. Based on these studies, the estimated near-fault ground motions from three Himalayan earthquakes have been interpreted.

Shapur Station: The orientation of recorded transverse (T) component of time-history at Shapur station due to the 1986 Dharamsala earthquake, demonstrated that it is in the FN direction provided that the fault-plane solution given by [37] is considered as the focal mechanism. The analysis of this record has been carried out using seven mother wavelets and the results obtained are listed in Table 4 It is evident from the values that both Daubechies wavelets $\mathrm{db} 4$ and $\mathrm{db} 7$ are capable of extracting the pulse-form from the velocity time history efficiently as both have pulse-indicators (PIs) above 0.85 and pulse-periods (Tp) of $0.53 \mathrm{sec}$ and $0.52 \mathrm{sec}$ respectively. However, the other wavelets are unable to extract the pulse-form efficiently from the recorded ground motion as the values of pulse-indicators (PIs) are below 0.85 . The spectral velocity curves of recorded ground motion and pulses identified using the two mother wavelets (db4 and db7) are plotted in Fig. 5. The plot shows that pulse-period (Tvp) associated with spectral velocity of ground motion is 

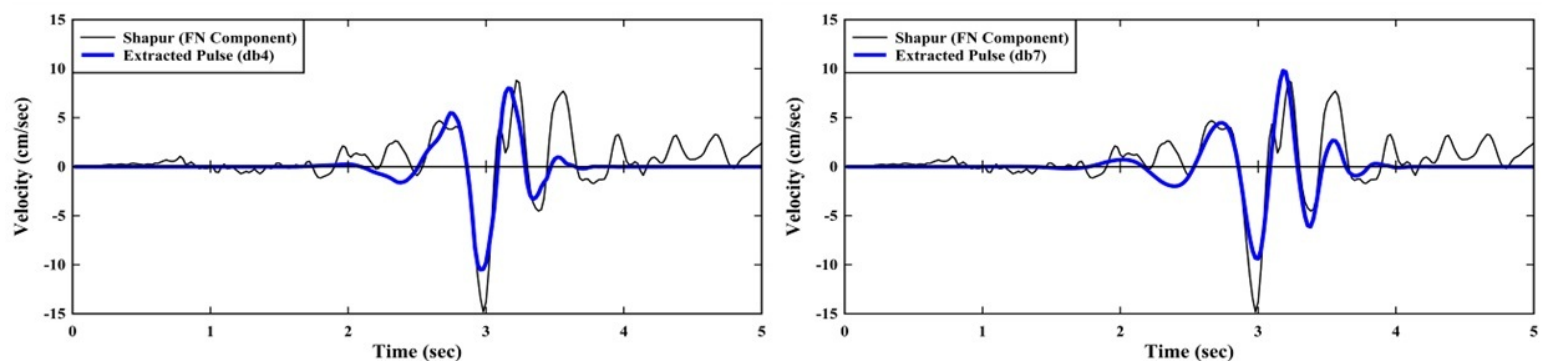

Fig. 2. FN component of recorded ground motion along with their extracted pulses (db4 and db7) at Shapur station
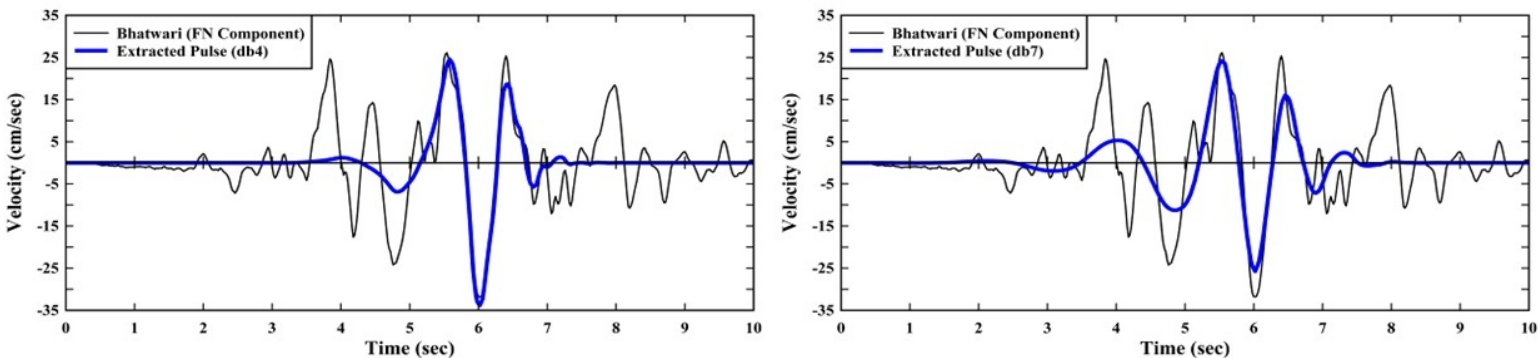

Fig. 3. FN component of recorded ground motion along with their extracted pulses (db4 and db7) at Bhatwari station
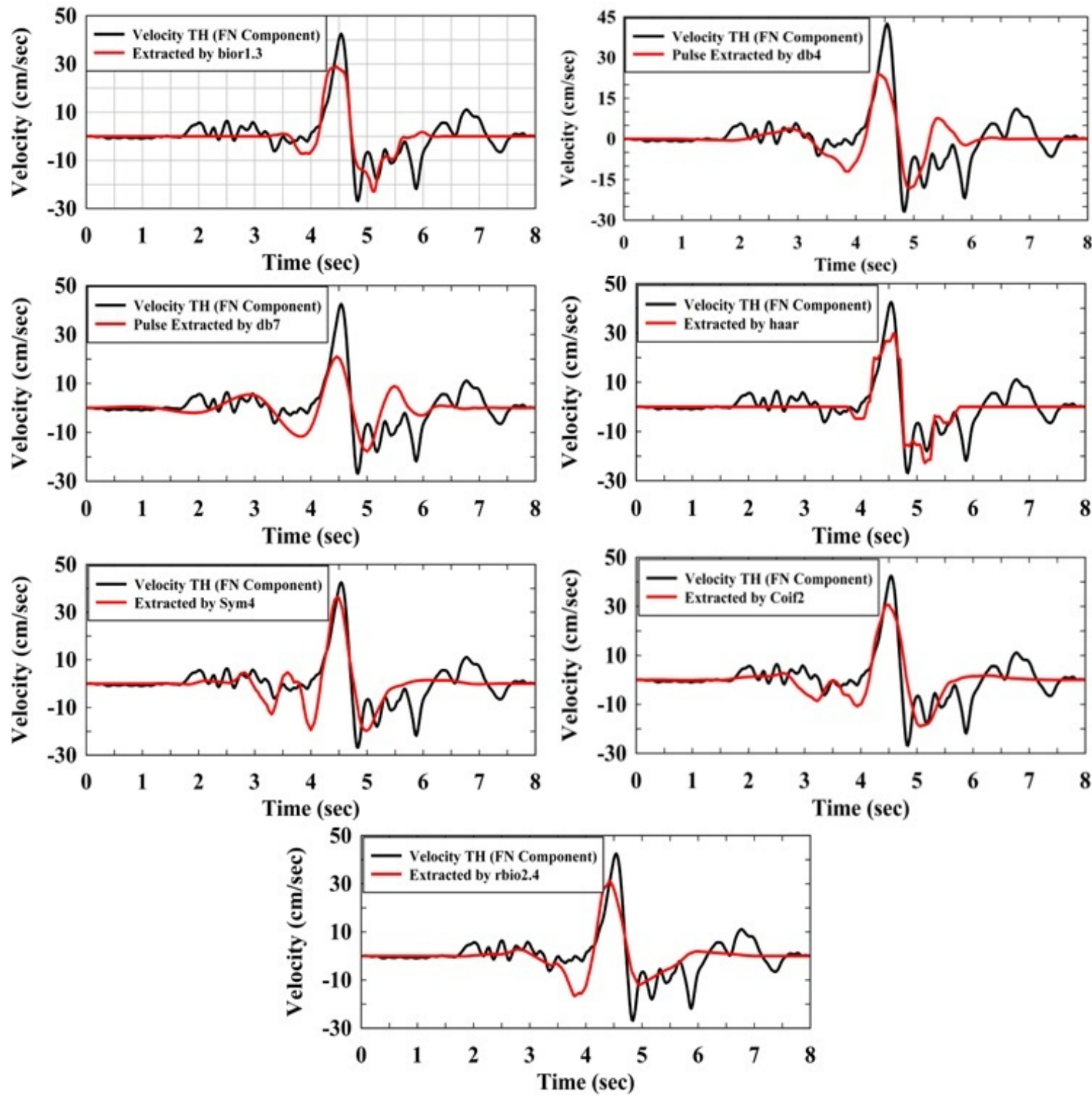

Fig. 4. FN component of recorded ground motion along with their extracted pulses (seven mother wavelets) at Gopeshwar Station 
Tab. 4. Pulse-indicators and pulse-periods using seven mother wavelets for FN component of ground motions at three stations

\begin{tabular}{ccccccc}
\hline \multirow{2}{*}{ Mother Wavelet } & \multicolumn{2}{c}{ Shapur (FN Component) } & \multicolumn{2}{c}{ Bhatwari (FN Component) } & \multicolumn{2}{c}{ Gopeshwar (FN Component) } \\
\cline { 2 - 7 } & $\begin{array}{c}\text { Pulse Indicator } \\
\text { (PI) }\end{array}$ & $\begin{array}{c}\text { Tp, Pulse Time } \\
\text { Period (sec) }\end{array}$ & $\begin{array}{c}\text { Pulse Indicator } \\
\text { (PI) }\end{array}$ & $\begin{array}{c}\text { Tp, Pulse Time } \\
\text { Period (sec) }\end{array}$ & $\begin{array}{c}\text { Pulse Indicator } \\
\text { (PI) }\end{array}$ & $\begin{array}{c}\text { Tp, Pulse Time } \\
\text { Period (sec) }\end{array}$ \\
\hline db4 & 0.9051 & 0.53 & 0.9112 & 1.09 & 0.9813 & 1.40 \\
db7 & 0.9431 & 0.52 & 0.9300 & 1.30 & 0.9019 & 1.39 \\
haar & 0.7631 & 0.40 & 0.5111 & 0.78 & 0.9996 & 1.08 \\
sym4 & 0.4241 & 0.59 & 0.5353 & 1.04 & 0.9886 & 1.37 \\
coif2 & 0.5692 & 0.55 & 0.4941 & 1.02 & 0.9624 & 1.54 \\
rbio2.4 & 0.6431 & 0.50 & 0.5307 & 1.15 & 0.9893 & 1.84 \\
bior1.3 & 0.8223 & 0.47 & 0.3633 & 0.90 & 0.9990 & 1.22 \\
\hline
\end{tabular}

$0.4 \mathrm{sec}$. By examining the shapes of the spectral velocity curves, it is observed that the pulse obtained using $\mathrm{db} 7$ wavelet is close to the pulse hidden in the ground motion, because spectral velocity curve of $\mathrm{db} 7$ wavelet is well matched and showed almost same trend as that of the spectral velocity curve of the recorded original ground motion in the intermediate-period-range compared to the pulse shape obtained using db4 wavelet. Hence, $\mathrm{db} 7$ wavelet is more efficient in extracting the pulse having pulseperiod (Tp) $0.52 \mathrm{sec}$ and pulse-indicator (PI) 0.94 than other wavelets at this station. Further, the value of pulse-indicator using $\mathrm{db} 7$ is larger than the value of pulse-indicator obtained from $\mathrm{db} 4$, which is 0.90 .

Bhatwari Station: On the similar lines, for obtaining FN component at Bhatwari station due to the 1991 Uttarkashi earthquake, the fault-plane solution given by [14] has been used. The velocity time-history of the FN component has been analyzed using seven mother wavelets. The extracted pulse-indicators and pulse-periods from the velocity time-history of the FN component are listed in Table 4. It is found that from the seven mother wavelets, Daubechies wavelets, $\mathrm{db} 4$ and $\mathrm{db} 7$, allowed the extraction of the pulse-form from the FN component as the values of pulse-indicators (PIs) are above 0.85 . The values of pulse-indicators obtained using seven mother wavelets including wavelets $\mathrm{db} 4$ and $\mathrm{db} 7$ vary between 0.36 and 0.93 . All the computed values of pulse-indicators are above 0.15 and show the varying pulsivity along with varying pulse-periods between $0.78 \mathrm{sec}$ and $1.30 \mathrm{sec}$. Computed spectral velocity curves of the FN component and the pulses extracted by $\mathrm{db} 4$ and $\mathrm{db} 7$ are shown in Fig. 6 Considering these variations in pulse-periods, and trend of the spectral velocity curve of FN component, it can be concluded that pulse-period (Tvp) associated with spectral velocity of FN component of ground motion is $1.30 \mathrm{sec}$. From the comparison of these spectral velocity curves, it is observed that pulse obtained by $\mathrm{db} 7$ wavelet is close to the pulse hidden in the FN component of ground motion because spectral velocity curve of $\mathrm{db} 7$ wavelet is well matched with almost similar trend with that of the FN component of ground motion in intermediate-period range. Thus, it is seen that $\mathrm{db} 7$ wavelet is more efficient than other wavelets in extracting the long-period pulse from the FN component of the ground motion. The estimated pulse-period (Tp) by using db7 mother wavelet is $1.30 \mathrm{sec}$ which is equal to spectral pulse-period $(1.30 \mathrm{sec})$ of the FN component. Further, the value of pulse-indicator (PI) using db7 is 0.93 which is greater than that of wavelet $\mathrm{db} 4$.

Gopeshwar Station: The FN component of ground motion at Gopeshwar station due to the 1999 Chamoli earthquake has been computed using the fault-plane solution given by [38]. The velocity time-history of the FN component has been analyzed for pulse detection adopting the seven mother wavelets. All the seven mother wavelets were capable of extracting the near-fault pulse from the computed FN component of ground motion, and it has been found that all mother wavelets gave values of pulseindicator (PI) above 0.85 with not much variation. However, a large variation in pulse-period between $1.08 \mathrm{sec}$ and $1.84 \mathrm{sec}$ has been observed as listed in Table 4 All the seven wavelets have pulse-indicators (PIs) above 0.85 , and it is important to decide which wavelet is better in extracting the parameters of the pulse-type ground motion. This can be achieved from the comparative study between pulse-periods (Tp) obtained using different wavelets and the spectral pulse-period (Tvp) of the FN component of ground motion, and by comparing the spectral shapes of extracted pulse-forms using seven mother wavelets with the spectral shape of the FN component of ground motion as shown in Fig. 77. Considering the variation in pulse-periods of extracted pulses, and time-periods associated with the peaks of the spectral velocity curve of the FN component, a long-period peak at $1.36 \mathrm{sec}$ (Tvp) has been observed. The period of this peak is above $1 \mathrm{sec}$, and is interpreted as spectral pulse-period (Tvp). The pulse-periods of extracted pulses for computed FN component are found to be less than $1.36 \mathrm{sec}$ (Tvp) using haar and bior1.3 wavelets. Whereas, the pulse-periods obtained using coif 2 and rbio2.4 wavelets are much higher than the spectral pulse-period (Tvp). However, pulse-periods obtained adopting $\mathrm{db} 4, \mathrm{db} 7$ and sym4 wavelets are slightly higher but closer to the spectral pulse-period (Tvp) of the FN component compared to pulse-periods obtained using other wavelets. Comparison of the spectral velocity curves of extracted pulses using $\mathrm{db} 4, \mathrm{db} 7$ and sym4 wavelets with spectral velocity curve of FN component of ground motion has revealed that spectral peak of sym 4 extracted pulse occurs before the long-period peak of FN component of ground motion. Further, the trends of the spectral curves obtained using db4 and db7 wavelets are very well correlated with 
the trend of spectral curve of FN component of ground motion. The matching in the trends of the curves seems to be more consistent above one sec period. From the above discussion, it is concluded that both mother wavelets (db4 and $\mathrm{db} 7$ ) are found to be better in extracting the pulse-form from the ground motion with pulse-periods (Tp) of $1.40 \mathrm{sec}$ and $1.39 \mathrm{sec}$, respectively.

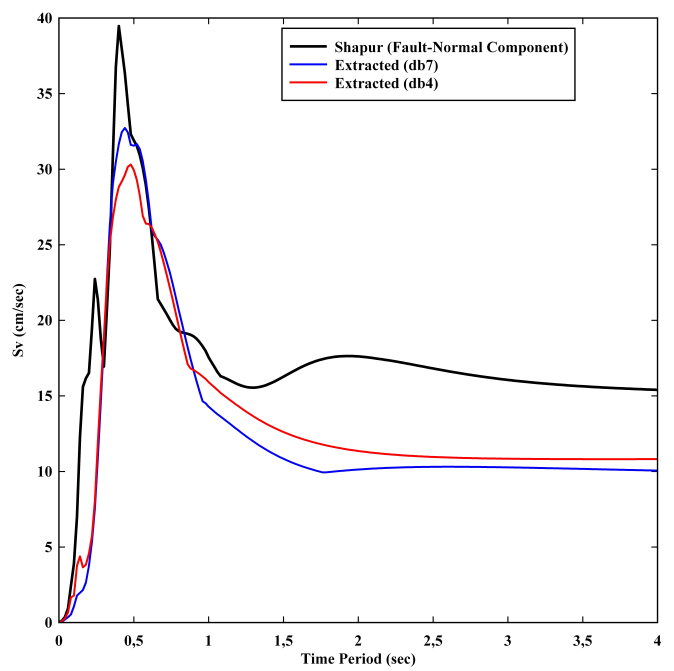

Fig. 5. Velocity spectra of FN component and extracted pulses (db4 and db7) at Shapur station

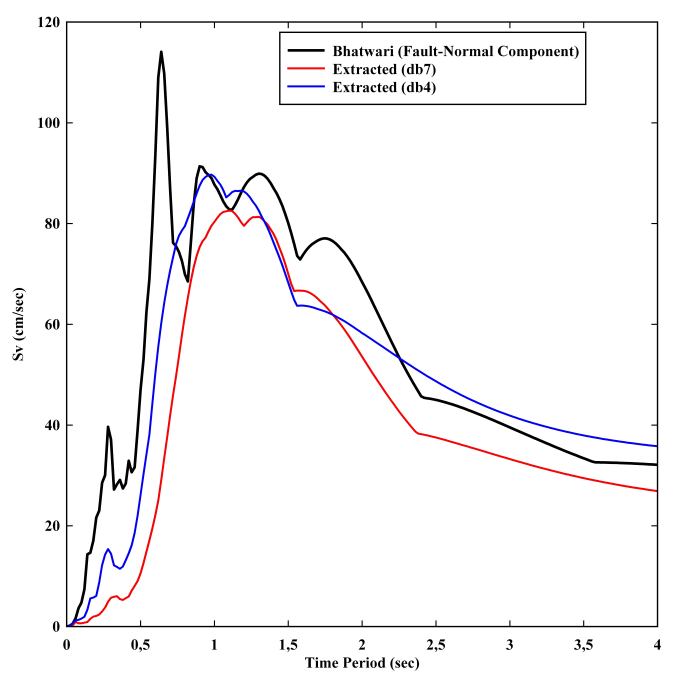

Fig. 6. Velocity spectra of FN component and extracted pulses (db4 and db7) at Bhatwari station

\section{Comparison of Near-Fault Response Spectra with In- dian Codal Response Spectra}

Fig. 8 shows the comparison of the normalized acceleration response spectra obtained from three near-fault FN components of ground motions of three moderate Himalayan earthquakes with the response spectra given in the Indian seismic code (IS 1893, Part 1). It is evident from this figure that spectral amplitudes are increasing at all periods with the increase in magnitudes, and show peaks in their elastic response spectra due to near-fault pulses in the time-history. Comparison of the three response spectra also shows that spectral amplitudes for smaller

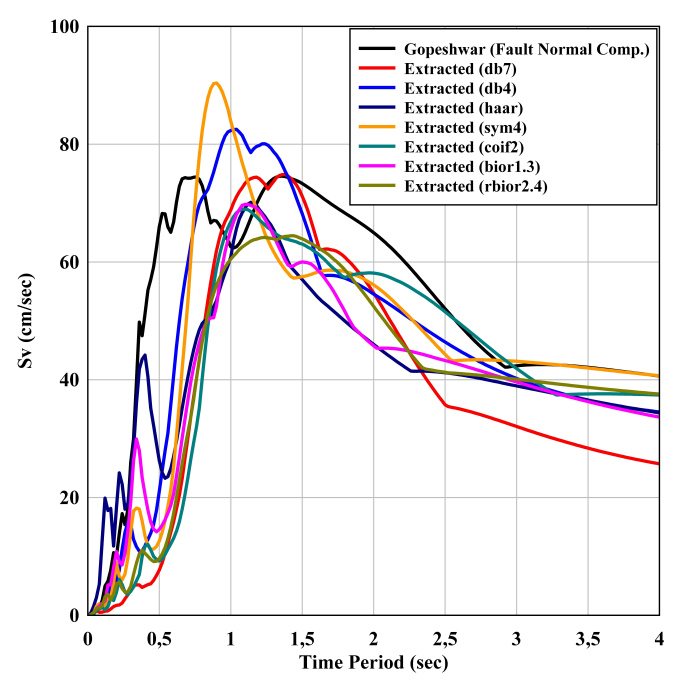

Fig. 7. Velocity spectra of FN component and extracted pulses (seven mother wavelets) at Gopeshwar station

earthquake $\left(M_{w}=5.5\right)$ may exceed at small and intermediate periods as observed at Shapur station because of the 1986 Dharamsala earthquake. Further, the spectral-amplitudes of near-fault ground motion at Shapur station are by and large compatible with IS code spectra in the period range from $0.1 \mathrm{sec}$ to $0.5 \mathrm{sec}$, barring one peak at $0.16 \mathrm{sec}$ with the spectral-amplitude of 2.91. However, with increase in period beyond $0.5 \mathrm{sec}$, the spectral values are low compare to the codal spectral values. The spectral values of FN component at Bhatwari station due to the 1991 Uttarkashi earthquake $\left(M_{w}=6.8\right)$ are much higher than the codal spectral values at intermediate and long periods upto $2 \mathrm{sec}$. As a consequence of this, the response of structures and buildings designed in the elastic range using the IS code shall not remain in the elastic range. Because of this the structures are likely to experience non-linear deformations and resulting damages. The spectral values of FN component of ground motion at Gopeshwar station due to the 1999 Chamoli earthquake $\left(M_{w}=6.5\right)$ are lower than the codal values upto $0.4 \mathrm{sec}$, and thereafter the spectral values increase upto $1.7 \mathrm{sec}$ with a hump at $0.8 \mathrm{sec}$. This hump shows the effect of long-period component of ground motion in the time-history.

According to the IS code [9], the Shapur and Gopeshwar stations are located in zone $\mathrm{V}$ whereas, Bhatwari station falls in zone IV, and all these three stations are located on hard rock. Fig. 9 shows a comparison of velocity spectra of the FN and transverse (T) components of ground motions at Shapur and Gopeshwar stations with codal velocity spectra, whereas, the similar comparison at Bhatwari station is shown in Fig. 10 These figures show that the characteristics of the near-fault ground motions are more clearly revealed in the velocity spectra, when compared with the codal velocity spectra. It is seen that the FN component of ground motion is more severe than the transverse $(\mathrm{T})$ component of ground motion at the Gopeshwar and Bhatwari stations. A comparison of the codal velocity spectra with the velocity spectra at Shapur station has demon- 


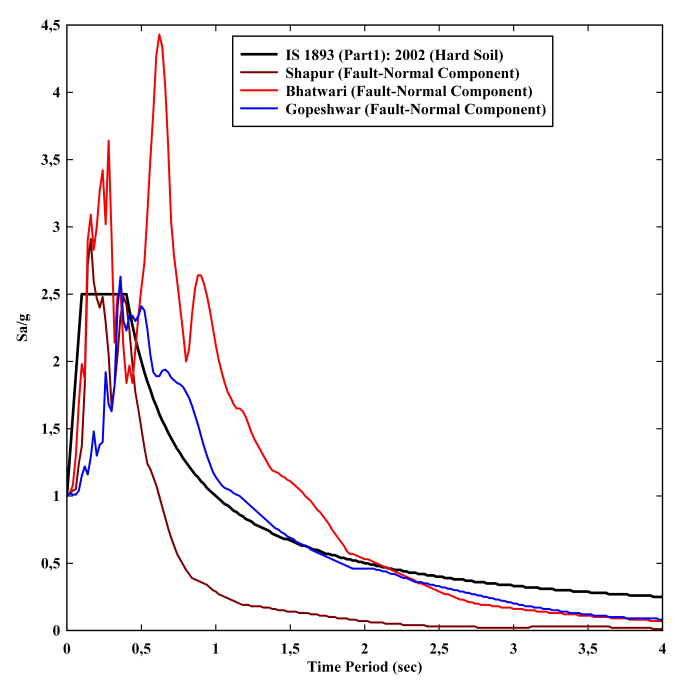

Fig. 8. Comparison of normalized accleration spectra for three near-fault fault-normal (FN) components of ground motions with Indian codal spectra

strated that the buildings designed according to IS code are safe, and the near-fault pulse-type ground motion due to small earthquakes $\left(M_{w} \sim 5.5\right)$ is of little consequence. A comparison of the velocity spectra of FN component at Gopeshwar station with the codal velocity spectra showed that the spectral values are on much higher side than the codal spectral values in the longperiod, ranging from $0.6 \mathrm{sec}$ to $2.3 \mathrm{sec}$. This contrasting observation is due to the higher PGV/PGA ratio at Gopeshwar station compared to Shapur station, and is related to the size of the earthquake.

Velocity spectra of the FN component at Bhatwari station shows higher spectral values at long-periods from $0.5 \mathrm{sec}$ to $3.1 \mathrm{sec}$ compared to the codal velocity spectral values (Fig. 10 . This finding is in agreement with that at Gopeshwar station and is attributed to long-period pulse present in the velocity timehistory.

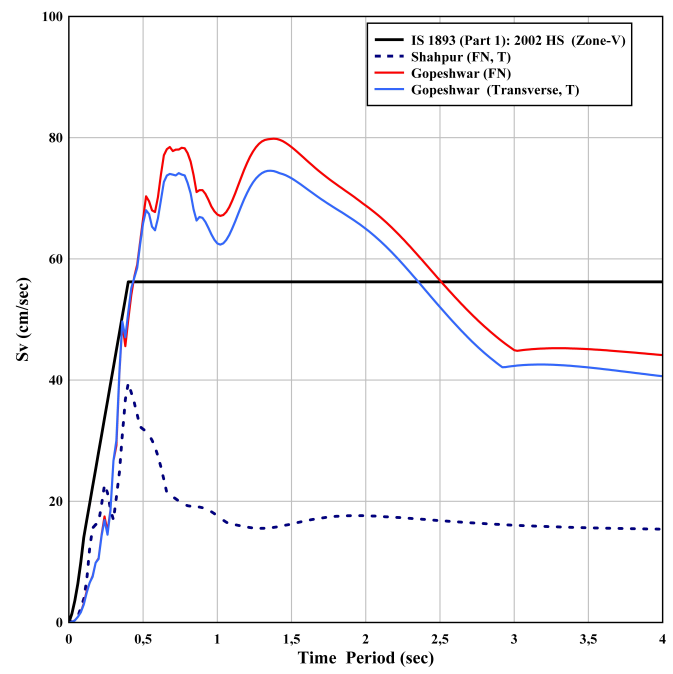

Fig. 9. Comparison of velocity spectra (FN and Transverse (T) Components) at Shapur and Gopeshwar stations with Indian codal spectra

Researcher [8] emphasized that for both the ordinary and pulse-like ground motions, the peak values of ground acceler-

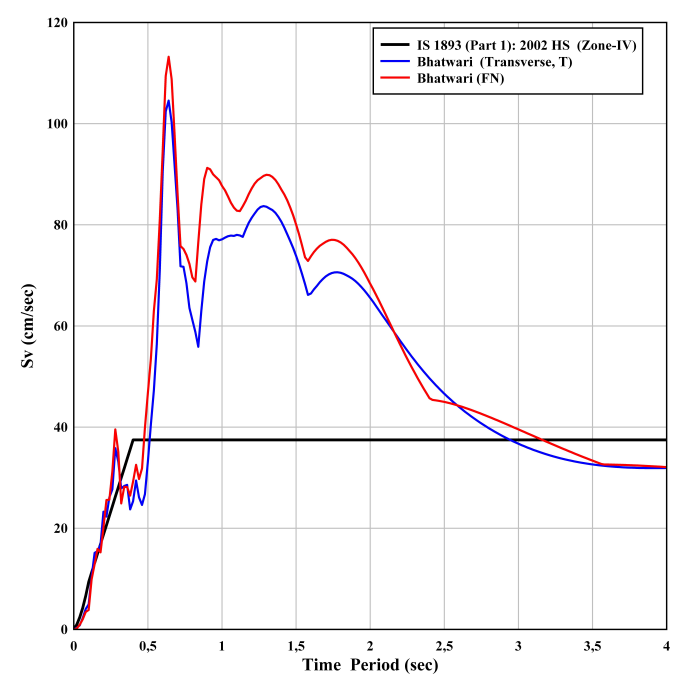

Fig. 10. Comparison of velocity spectra (FN and Transverse (T) Components) at Bhatwari station with Indian codal spectra

ation (PGA), velocity (PGV), and displacement (PGD) are the important response parameters. However, for near-fault pulsetype ground motion, the width of acceleration-sensitive region increases in the triparitite plot due to the high PGV/PGA ratio. To verify this observation, the tripartite plots of 5\% damped elastic response spectra of FN components of ground motions at Shapur and Gopeshwar stations are compared with the codal response spectra for zone V in Fig. 11. Similarly, the FN component at Bhatwari station is compared with the codal response spectra for zone IV in Fig. 11. In these plots, the natural period " $T$ " is along the horizontal axis, pseudo-spectral velocity along the vertical axis, pseudo-spectral acceleration along the $-45^{\circ}$ axis, and the spectral displacement along the $+45^{\circ}$ axis.

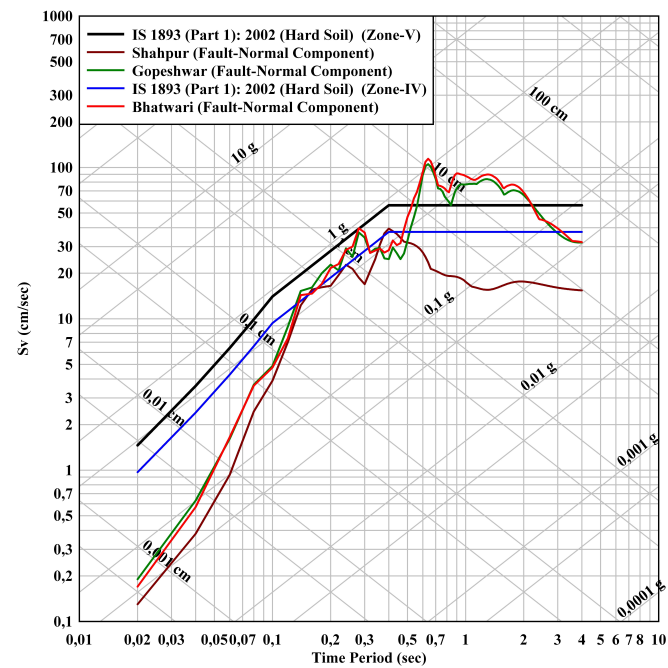

Fig. 11. Tripartite plot (5\% damping) showing the comparison of spectral amplitudes of fault-normal (FN) components of ground motions at Shapur, Gopeshwar and Bhatwari stations with Indian codal spectra

In the tripartite plot the middle region, with constant pseudo-spectral velocity, signifies the velocity-sensitive region, whereas; to the left and right of this region represent the acceleration-sensitive and displacement-sensitive regions re- 
Tab. 5. Widths of acceleration-sensitive region of three near-fault FN component

\begin{tabular}{ccccccc}
\hline Earthquakes & Station & $\mathbf{M}_{\mathbf{w}}$ & PGA (g) & $\begin{array}{c}\text { PGV } \\
\text { (cm/sec) }\end{array}$ & $\begin{array}{r}\text { PGV/PGA } \\
\text { (sec) }\end{array}$ & $\begin{array}{c}\text { Width of ac- } \\
\text { celeration } \\
\text { sensitive } \\
\text { region (sec) }\end{array}$ \\
\hline Dharamsala & Shapur & 5.5 & 0.248 & 14.3 & 0.06 & 0.35 \\
Uttarkashi & Bhatwari & 6.8 & 0.253 & 31.8 & 0.13 & 0.65 \\
Chamoli & Gopeshwar & 6.5 & 0.343 & 43.3 & 0.13 & 0.53 \\
\hline
\end{tabular}

spectively [35]. The amplitudes of PGA, PGV and PGD control the spectral amplitudes in these three regions, while the widths of the three regions depend on the ratios of PGV/PGA and PGD/PGV. The higher PGV/PGA ratio leads to the widening of acceleration-sensitive region, whereas the lower PGD/PGV ratio leads to the widening of displacement-sensitive region [8]. Table 5 shows a comparison of the widths of acceleration-sensitive region obtained from the tripartite plot of three near-fault FN ground motions (Fig. 11). Table 5 shows that at Shapur station the acceleration-sensitive region extends up to $0.35 \mathrm{sec}$ because of the ground motion due to Dharamsala earthquake. This value is slightly less than the codal value of $0.40 \mathrm{sec}$. Considering the FN components of ground motions of the Uttarkashi and Chamoli earthquakes, the acceleration-sensitive regions at Bhatwari and Gopeshwar stations extend up to $0.65 \mathrm{sec}$ and $0.53 \mathrm{sec}$, respectively. These values are higher than the codal value of $0.40 \mathrm{sec}$. These widenings of acceleration-sensitive regions are due to the higher PGV/PGA ratios for these two ground motions. The velocity-sensitive regions in the tripartite plot show that at Bhatwari and Gopeshwar stations the spectral amplitudes are higher than the codal spectral amplitudes (Fig. 11). However, at Shapur station the spectral amplitudes are lower compared to the codal spectral amplitudes. In a nutshell, the acceleration-sensitive regions of near-fault ground motions for the Uttarkashi and Chamoli earthquakes are wider than the acceleration-sensitive region given by the IS code. Current IS code does not have a provision to include the effect of near-fault ground motions. In view of this there is a need to revise the design spectrum given in the IS code to incorporate the effect of near-fault ground motions for sites located in the vicinity of seismically active faults.

\section{Conclusions}

For the three Himalayan earthquakes, Daubechies mother wavelets of order four (db4) and seven (db7) are found to be more efficient in extracting the pulse-type characteristics from the near-fault strong ground motion recordings. However, the spectra of long-period pulses extracted using Daubechies mother wavelet of order seven (db7) are closer to the long-period spectral amplitudes of the FN components of ground motions at three sites. For the Dharamsala earthquake, FN component of ground motion at Shapur station showed pulse-type ground motion with the pulse-period (Tp) $0.52 \mathrm{sec}$ and pulse-indicator 0.94. For the Uttarkashi and Chamoli earthquakes, computed
FN components at Bhatwari and Gopeshwar stations showed pulse-type ground motion in their velocity time-histories. At Bhatwari and Gopeshwar stations the pulse-periods of FN components are $1.30 \mathrm{sec}$ and $1.39 \mathrm{sec}$ respectively.

A comparison of velocity spectra at Shapur station with codal spectra has demonstrated that the buildings designed according to the IS code are safe, and that the near-fault pulse-type ground motion produced due to small earthquakes $\left(M_{w} \sim 5.5\right)$ is of little consequence. The spectral values of FN component at Bhatwari station due to the Uttarkashi earthquake are much higher than the codal spectral values at intermediate and long periods. The spectral values of FN component at Gopeshwar station due to the Chamoli earthquake are lower than the codal values by upto $0.4 \mathrm{sec}$, and then the spectral values increase upto $1.7 \mathrm{sec}$, with a hump at $0.8 \mathrm{sec}$ which shows the effect of long-period component in the time-history. As a consequence of this, the response of structures and buildings with fundamental period above $0.4 \mathrm{sec}$ designed using the IS code may not remain in the elastic range, and are likely to experience non-linear deformations and resulting damages.

At Shapur station the width of the acceleration-sensitive region is slightly less compared to the IS code and the spectral amplitudes are lower compared to the codal spectral amplitudes. This is attributed to small size of the Dharamsala earthquake compared to the Uttarkashi and Chamoli earthquakes. In a nutshell, the acceleration-sensitive regions due to near-fault ground motions of the Uttarkashi and Chamoli earthquakes have higher width than that given by the IS code. Because of this, the structures designed to be flexible in the intermediate-period and longperiod range will behave as stiff structures, and subjected to increased base shear. Current IS code (IS: 1893 (Part1): 2002) does not account for this widening of the acceleration-sensitive region which occurs due to the effect of NFGM. This aspect should be incorporated in the IS code for designing structures located in the vicinity of seismically active faults in the Himalayan region.

Spectral characteristics of near-fault pulse-type ground motions due to the Uttarkashi and Chamoli earthquakes have illustrated that the IS code is deficient in addressing the long-period near-fault ground motions, particulary for the Himalayan regions. Therefore, the IS code needs modification, and the effect of NFGM in terms of increasing spectral amplitudes towards long-periods should be incorporated in the design spectrum. Be- 
cause of lack of sufficient number of near-fault recordings, the present study is unable to recommmend a specific design spectra for near-fault sites. In the future when sufficient data shall be available, it may be possible to arrive at a specific NFGM design spectra.

\section{References}

1 Chandrasekekran AR, Strong motion arrays in India, Ninth World Conference on Earthquake Engineering, In: Proceedings of Ninth World Conference on Earthquake Engineering, Japan Association for Earthquake Disaster Prevention; Tokyo-Kyoto, Japan, 1988, pp. 131-136. Vol.VIII.

2 Khattri KN, Tyagi AK, Seismicity pattern in the Himalayan plate boundary and identi? cation of areas of high seismic potential, Tectonophysics, 96(3-4), (1983), 281-297, DOI 10.1016/0040-1951(83)90222-6

3 Chandrasekekran AR, Das JD, Strong motion records from Uttarkashi earthquake, Geological Society of India, 30(1), (1995), 133-147.

4 Baker JW, Quantitative classification of near-fault ground motions using wavelet analysis, Bulletin of Seismological Society of America, 97(5), (2007), 1486-1501, DOI $10.1785 / 0120060255$

5 Shuang L, Xie L, Progress and trend on near-field problems in civil engineering, Acta. Seismologica. Sinica, 20(1), (2007), 105-114, DOI 10.1007/s11589-007-0105-0

6 Yang DX, Pan JW, Li G, Non-structure-specific intensity measure parameters and characteristic period of near-fault ground motions, Earthquake Engineering and Structural Dynamics, 38(11), (2009), 1257-1280, DOI 10.1002/eqe.889

7 Yang DX, Zhou JL, A stochastic model and synthesis for near-fault impulsive ground motions, Earthquake Engineering and Structural Dynamics, 44(2), (2015), 261-282, DOI 10.1002/eqe.2468

8 Malhotra PK, Response of building to near-field pulse-like ground motions, Earthquake Engineering and Structural Dynamics, 28(11), (1999), 1309-1326, DOI 10.1002/(SICI)1096-9845(199911)28:11<1309::AIDEQE868>3.0.CO;2-U

9 IS 1893 (Part 1), Criteria for earthquake resistant design of structures-general provisions and buildings, Bureau of Indian Standards.; New Delhi, 2002.

10 Kayal JR, Recent large earthquakes in India: Seismotectonic Perspective, International Association for Gondwana Research, Japan, 10, (2007), 189199.

11 Kumar S, Mahajan AK, Seismotectonics of the Kangra region, northwest Himalaya, Techonophysics, 331(4), (2001), 359-371, DOI 10.1016/S00401951(00)00293-6

12 Joshi A, Modeling of rupture planes for peak ground accelerations and its application to the isoseismal map of MMI scale in Indian region, Journal of Seismology, 4(2), (2000), 143-160, DOI 10.1023/A:1009853408741

13 Thakur VC, Kumar S, Seismotectonics of the 20 October 1991 Uttarkashi earthquake in Garhwal, Himalaya, north India, Terra Nova, 6(1), (1994), 90-94, DOI 10.1111/j.1365-3121.1994.tb00637.x

14 Paul A, Sharma ML, Singh VN, Estimation of focal parameters of Uttarkashi earthquake using peak ground horizontal accelerations, ISET Journal of Earthquake Technology, 35(1-3), (1998), 1-8.

15 Chander R, Gahalaut K, Evidence from earthquake fault plane solutions on upper crustal stresses in the Garhwal, Himalaya Journal of the Geological Society of India, 45(6), (1995), 695-701.

16 Joshi A, Singh S, Giroti K, The simulation of ground motions using envelope summations, Pure Applied Geophysics, 158(5-6), (2001), 877-901, DOI 10.1007/PL00001211

17 Shrikhande M, Rai DC, Narayan JP, Das JD, The March 28, 1999 earthquake at Chamoli, India, 12th World Conference on Earthquake Engineering, In: Proceedings of the Twelfth World Conference on Earthquake Engi- neering, Upper Hutt, N.Z.:New Zealand Society for Earthquake Engineering; New Zealand, Auckland, 2000. pp. 8 Paper No. 2838.

18 Rathje EM, Faraj F, Russell S, Bray JD, Empirical relationships for frequency content parameters of earthquake ground motions, Earthquake Spectra, 20(1), (2004), 119-144, DOI 10.1193/1.1643356

19 Maniatakis CA, Taflampas IM, Spyrakos CC, Identification of near-fault earthquake record characteristics, 14th World Conference on Earthquake Engineering, In: Proceedings of the 14th World Conference on Earthquake Engineering, IAEE and CAEE, Mira Digital Publishing, Saint Louis; Beijing, China, 2008. pp. 8.

20 Alavi B, Krawinkler $\mathbf{H}$, Consideration of near-fault ground motion effects in seismic design, 12th World Conference on Earthquake Engineering, In: Proceedings of the Twelfth World Conference on Earthquake Engineering, Upper Hutt, N.Z.:New Zealand Society for Earthquake Engineering; New Zealand, Auckland, 2000. pp. 8 Paper No. 2665.

21 Mavroeidis GP, Dong G, Papageorgiou AS, Near-fault ground motion and the response of elastic and inelastic single-degree-of-freedom (SDOF) systems, Earthquake Engineering and Structural Dynamics, 33(9), (2004), 1023-1049, DOI 10.1002/eqe.391

22 Hall JF, Heaton TH, Halling MW, Near-source ground motion and its effects on flexible buildings, Earthquake Spectra, 11(4), (1995), 569-604, DOI 10.1193/1.1585828

23 Xin-le L, Xi Z, Study on equivalent velocity pulse of near-fault ground motions, Acta Seismologica Sinica, 17(6), (2004a), 697-706, DOI 10.1007/s11589-004-0009-1

24 Agrawal AK, He WL, A close-form approximation of near-fault ground motion pulses for flexible structures, 15th ASCE Engineering Mechanics Conference, In: Smyth AW (ed.), Proceedings of EM2002, the 15th ASCE Engineering Mechanics Conference, American Society of Civil Engineers, NY: Columbia University; New York: Columbia University, 2002, pp. 131-138. Paper No. 367.

25 Menun C, Fu Q, An analytical model for near-fault ground motions and the response of SDOF systems, 7th US National Conference on Earthquake Engineering, In: Dunai L, Iványi M, Kovács N, Vigh LG (eds.), Proceedings of the Seventh U.S. National Conference on Earthquake Engineering, Earthquake Engineering Research Institute; Boston, Massachusetts, 2002. pp. 10 Paper No. 00011.

26 Fu Q, Menun C, Seismic-environment-based simulation of near-fault ground motions, 13th World Conference on Earthquake Engineering, In: Proceedings of 13th World Conference on Earthquake Engineering, 13 WCEE Secretariat Publisher, Vancouver, B.C.; Vancouver B C, Canada, 2004. pp. 15 Paper No. 322

27 Sabegh SY, Detection of pulse-like ground motions based on continues wavelet transform, Journal of Seismology, 14(4), (2010), 715-726, DOI 10.1007/s10950-010-9193-8

28 Gurley K, Kareem A, Application of wavelet transformations in earthquake, wind and ocean engineering, Engineering Structures, 21(2), (1999), 149_ 167.

29 Rezai M, Ventura CE, Analysis of strong and weak ground motions recorded at two sites during Loma Prieta earthquake by wavelet transform, Canadian Journal of Civil Engineering, 29(1), (2002), 157-170, DOI 10.1139/101-077

30 Alavi B, Krawinkler H, Effects of near-fault ground motions on frame structures, The John A. Blume Earthquake Engineering Center; Stanford University, 2001. Report No. 138.

31 Anderson J, Bertero V, Uncertainties in establishing design earthquakes, ASCE Journal of Structural Engineering, 113(8), (1978), 1709-1724, DOI 10.1061/(ASCE)0733-9445(1987)113:8(1709)

32 Anderson J, Bertero V, Bertero R, Performance improvement of long period building structures subjected to severe pulse-type ground motion, Pacific Earthquake Engineering Research Center; University of California, Berkeley, 1999. Report No. PEER-1999/09. 
33 Bertero V, Mahin S, Herrera R, Aseismic design implications of near-fault San Fernando earthquake records, Earthquake Engineering and Structural Dynamics, 6(1), (1978), 31-42, DOI 10.1002/eqe.4290060105

34 Bray JD, Marek AR, Characterization of forward-directivity ground motions in the near-fault region, Soil Dynamics and Earthquake Engineering, 24(11), (2004), 815-828, DOI 10.1016/j.soildyn.2004.05.001

35 Chopra AK, Chintanapakdee C, Comparing response of SDOF system to near-fault and far-fault earthquake motions in the context of spectral regions, Earthquake Engineering and Structural Dynamics, 30(12), (2001), 17691789, DOI $10.1002 /$ eqe. 92

36 Somerville PG, Characterizing near fault ground motion for the design and evaluation of bridges, Third National Seismic Conference and Workshop on Bridges and Highways, In: Nimis R, Bruneau M (eds.), The Proceedings of the Third National Seismic Conference and Workshop on Bridges and Highways, MCEER Publications, University at Buffalo, State University of New York; Portland, Oregon, 2002, pp. 137-148. Session 5.

37 Molnar $\mathbf{P}$, Lyon-Caen $\mathbf{H}$, Fault plane solutions of earthquakes and active tectonics of the Tibetan plateau and its margins, Geophysical Journal International, 99(1), (1989), 123-153, DOI 10.1111/j.1365-246X.1989.tb02020.x

38 Kumar D, Ram VS, Khattri KN, A study of source parameters, site amplification functions and average effective shear wave quality factor qseff from analysis of accelerograms of the 1999 Chamoli earthquake, Himalaya, Pure and Applied Geophysics, 163(7), (2006), 1369-1398, DOI 10.1007/s00024006-0078-2 